\title{
Revisiting the Health and Wellness Benefits of Lifetime Sports to Aging Individuals 25 Years Later
}

\author{
Irving H. Smith \\ Department of Health \& Health Education, Coppin State University, Baltimore, MD 21216, USA
}

\begin{abstract}
Revisiting the Health and Wellness Benefits of Lifetime Sports to Aging Individuals 25 Years Later is an adaptation of Revisiting the Health and Wellness Benefits of Exercise, Physical Activity and Lifetime Sports Participation to Aging Individuals 25 Years Later that was presented orally at the International Health Conference at King's College, London, England in June 2016. The study was initiated in 1991 in Prince George's County, Maryland based upon the conceptual framework of published research determining that high intensity strength training in nonagenarians, persons in the 90 -year old range, was beneficial to their overall health and well-being. More older individuals are living longer throughout the world and many of these aging individuals are healthy enough to actually enjoy their longevity. One of the main reasons for the improvements in longevity and functional health is many more aging individuals are better educated about what constitutes good health and are more accepting of those behavioral factors that contribute to good health such as increasing physical activity and initiating or maintaining active involvement in lifetime sports pursuits.
\end{abstract}

Key words: Lifetime sports, master athletes, health \& wellness.

A 1991 analysis of senior center activity logs and physical activity class attendance rosters in Prince Georges County, Maryland determined that one half of the senior center patrons between the ages of 55 and 84 years were not participating in any form of exercise, physical activity or lifetime sports programs or activities. Three distinct studies and their subsequent programs spanning more than 15 years emerged as a result of that analysis. The first study was designed to improve the health and well-being of the older citizens of Prince George's County, Maryland through a year round program of lifetime sports and high adventure activities [1]. This first study included an analysis of the pre-existing data including service data sources and social indicator data, key informant surveys, and an open-ended questionnaire that took a life history approach and produced largely quantitative data results. Findings from the pre-existing data revealed a steady increase in participation levels at the Maryland Senior

Corresponding author: Irving H. Smith, Ph.D., Health \& Health Education Chair/Professor, research field: health sciences, sports science, advanced gerontology, behavioral health, health inequity, social determinants of health.
Games by senior athletes from Prince George's County beginning in 1991 as a result of the year round lifetime sports program designed to improve health and well-being. The greatest number of Prince George's County older athletes who participated in the Maryland Senior Games participated in track and field, aquatics, basketball, bowling, tennis and cycling. The largest percentage of participants by age was those between 60-64 years. An equal number of participants represented the 55-59 age group and the 65-69 age group. The oldest Prince George's County participant was in the 85-89 age group. One senior athlete began participating in the U.S. Marine Corps Marathon and continued participating for more than 15 years. Another senior athlete of that time period is still competing at the age of 80. Data collected at the 1985 World Master's Games in Toronto [2] found that even those older athletes who only participated marginally enjoyed higher levels of overall health and well-being than their more sedentary counterparts. Master Athletes who train vigorously for athletic competitions resemble many younger athletes in terms of such 
factors as aerobic power, lower blood pressure, and lean body mass [3, 4]. Programs that enable older persons to develop and maintain good exercise and physical activity habits throughout the lifespan contribute to functional independence and overall well-being. Those older individuals who participate in sports pursuits enjoy an even higher level of optimal health and well-being on into their eighth and ninth decades.

The second study analyzed the barriers, determinants, and predictors of participation in exercise, physical activity and lifetime sports programs for older individuals [5]. Research suggests that even though many older persons may be willing participants in exercise, physical activity and lifetime sports programs, little is known about the predictors of their participation. This study utilized a cross-sectional closed and open-ended questionnaire that produced mainly quantitative findings. A pool of more than 100 respondents between the ages of 55 and 84 years was chosen from lists of members of seniors' programs in six municipal areas of Prince George's County, Maryland. A nonprobability convenience sample was used to select the subjects. Results from the regression analysis indicated that perceptions of health, perceived benefits of participation, educational level, and socioeconomic level were predictors of participation. Findings of these studies can be generalized to the larger population of aging individuals. When it came to health-related issues, the family physician was a trusted source of health-related information and advice. However, most larger clinical studies of physical activity programs did not focus on older adults because older adults were considered poor participants in clinical research studies. The most commonly reported factor for their nonparticipation was the objections of the participants' physician, family members, or significant other [6]. While the desire to improve one's health is usually a good motivator for starting an exercise or physical activity program, a physician's order to increase physical activity is usually a much more convincing reason to begin or increase physical activity [7]. However, a 1985 survey of physician's views toward physical activity and lifetime sports participation for older individuals found that many physicians were hesitant about counseling their patients on such health-related behaviors as physical activity and lifetime sports [8]. This survey of a national sample of family practice physicians revealed that approximately $67 \%$ did not believe in their patient's ability to change and $30 \%$ did not feel that they had the appropriate training to counsel their patients on matters related to physical activity and lifetime sports participation.

According to the Health Belief Model, older persons become more sedentary as a result of their beliefs concerning the risk/benefit ratio of exercise, physical activity and particularly lifetime sports participation and as a result, the kinds of beliefs older women held concerning the barriers to participation in exercise, physical activity and lifetime sports programs was studied by surveying one hundred and forty-three older women, 70 years and older. It was found that most of these women were well aware of the benefits of participation but their awareness did not decrease their fears and concerns as to the risks [9]. Only a few studies have been conducted that focus on the exercise and physical activity patterns of racial minorities. In a study of a nationally representative sample of older persons, it was found that rates of physical activity participation were low among white Americans and even lower among African Americans [10]. Of the 246 healthy older subjects in one study, only five were minorities [11]. Measures of exogenous variables included, among many others, perceived health status, life values, health locus of control, health belief model, barriers, benefits, cues to action, and susceptibility to health problems. The perceived health status of the respondents was measured utilizing a scale of health [12]. Life values were measured utilizing the value survey [13] and beliefs concerning the risk/benefits ratio was measured utilizing the Health Belief Model 
[14]. Among the independent variables, there were many significant relationships. There were two associations that served as initial indicators of multicollinearity. Multicollinearity occurs when there are independent variables that are strongly correlated to each other. The first is the association between perceptions of health and life values. The second potential indicator of multicollinearity occurred between cues to action and benefits. Correlation analyses were performed on the exogenous independent variables. Results suggest that perception of health and life values both have moderately strong correlations to exercise, physical activity and lifetime sports participation. The association between locus of control and exercise, physical activity and even lifetime sports participation was moderately correlated indicating that the more control an individual has over his or her health, the more prone he or she is to be involved in exercise, physical activity and lifetime sports programs.

Not only are more older individuals living longer but they strongly desire to remain independent and functional in their own homes and communities. This phenomenon is commonly referred to as "aging in place." When an older person's health begins to decline, it begins to adversely impact upon this independence. Many more older persons are much better educated about nutrition and about such health behaviors as exercise, physical activity and lifetime sports participation. Programs that enable older persons to develop and maintain good physical activity habits throughout their lifetime contribute to their independence and their well-being. As a result of the two aforementioned studies on exercise, physical activity and lifetime sports participation and their subsequent exercise, physical activity and lifetime sports programs, the third previously mentioned study was undertaken in Prince George's County, Maryland. That study tracked, charted, and measured the centenarian (100-year old) and nonagenarian population of the county. It was hypothesized that the true measure of the health and wellness benefits of exercise, physical activity and lifetime sports participation to aging individuals in Prince George's County would have to be revealed in the functional longevity of the county's oldest citizens. It was found that not only were more older persons in the County living longer, they were healthy enough and physically fit enough to enjoy their longevity. Every year since 1993 this research has found more than 150 centenarians and nonagenarians per year living in Prince George's County, Maryland, most of them still living in their own homes and communities, aging in place.

\section{References}

[1] Smith, I. H. 1995. "Off Your Rocker: Improving the Health and Psychological Well-being of the Older Citizens of Prince George's County, Maryland Through a Year 'Round Program of Lifetime Sports and High Adventure Activities." Master's Degree Thesis, Lincoln University.

[2] Kavanagh, T., and Shephard, R. J. 1990. "Can Regular Sports Participation Slow the Aging Process?: Data on Master Athletes." The Physician and Sportsmedicine 18 (6): 94-104.

[3] Piscopo, J. 1982. "Fitness and Aging." The Easterner 7 (1): 2-6.

[4] Shephard, R. J., and Kavanagh, T. 1978. "The Effects of Training on the Aging Process." The Physician and Sportsmedicine 6 (1): 32-40.

[5] Smith, I. H. 2002. "Barriers, Determinants, and Predictors of Participation in Exercise, Physical Activity, and Lifetime Sports Programs for Older Individuals.” Doctoral Dissertation, Walden University.

[6] Carter, W. B., Elward, K, Malmgren, J, Martin, M. L., and Larson, E. 1991. "Participation of Older Adults in Health Programs and Research: A Critical Review of the Literature." The Gerontologist 31 (5): 584-92.

[7] Ward, A., Taylor, P., and Ripple, J. 1991. "How to Tailor Your Exercise Program." The Physician and Sportsmedicine 19 (9): 64-74.

[8] Orlean, C. T., George, L. K., Houpt, J. L., and Brodie, K. 1985. "Health Promotion in Primary Care: A Survey of U.S. Family Practitioners." Preventive Medicine 14 (5): 636-47.

[9] O’Brien-Cousins, S. 2000. "My Heart Couldn't Take It: Older Women's Beliefs about Exercise Benefits and Risks.” Journal of Gerontology 55 (5): P283-94. 
[10] Clark, D. O. 1995. "Racial and Educational Differences in Physical Activity among Older Adults." The Gerontologist 35 (4): 472-80.

[11] Smith, C. L., and Storandt, M. 1997. "Physical Activity Participation in Older Adults: A Comparison of Competitors, Noncompetitors, and Nonexercisers." Journal of Aging and Physical Activity 5 (2): 98-110.

[12] Willits, F., and Crider, D. 1988. "Health Rating and Life Satisfaction in Later Years." Journal of Gerontology 43
(5): $172-6$

[13] Wallston, K. 1991. "The Importance of Placing Measures of Health Locus of Control Beliefs in a Theoretical Context." Health Education Research 6 (2): 251-2.

[14] Hayslip, B., Weigand, D., Weinberg, R., Richardson, P., and Jackson, A. 1996. "The Development of New Scales for Assessing Health Belief Model Constructs in Adulthood." Journal of Aging and Physical Activity 4 (4): 307-23. 